\title{
Correlation between Excessive Daytime Sleepiness (EDS) and self-reported and objective nasal characteristics*
}

\author{
Kristin Marie Hoven' ${ }^{1}$, Hans-Jørgen Aarstad ${ }^{1,2}$, Bjørn Bjorvatn ${ }^{3,5}$, Erlend \\ Haugen Lundemo', Sverre K. Steinsvåg ${ }^{1,2,4}$ \\ ' Department of Otolaryngology, Head and Neck Surgery, Haukeland University Hospital, 5021 Bergen Norway \\ 2 Department of Clinical Medicine, Faculty of Medicine and Dentistry, University of Bergen, Bergen, Norway \\ ${ }^{3}$ Norwegian Competence Center for Sleep Disorders, Haukeland University Hospital, 5021 Bergen Norway \\ ${ }^{4}$ Department of Otolaryngology, Head and Neck Surgery, Sørlandet Hospital, 4604 Kristiansand, Norway \\ 5 Department of Global Public Health and Primary Care, University of Bergen, Norway
}

Rhinology 56: 316-322, 2018

https://doi.org/10.4193/Rhin.17.203

*Received for publication:

September 19, 2017

Accepted: March 18, 2018

Background: The aim of the present study was to explore the relationship between excessive daytime sleepiness (EDS), Peak Nasal Inspiratory Flow (PNIF), and patient reported symptoms from the nose.

Methology: Six hundred and fifty one consecutive patients referred to a hospital on suspicion of sleep related breathing disorder (SRBD) were included in the study. Daytime sleepiness was assessed by Epworth Sleepiness Scale (EpSS). Nasal airflow was measured with Peak Nasal Inspiratory Flow (PNIF). Symptoms of sino-nasal dysfunction and diseases were graded on Visual Analogue Scales (VAS).

Results: EpSS score was not correlated with nasal flow as measured by PNIF or nasal obstruction -VAS scores. There were significant associations between daytime sleepiness and patient-reported VAS-scores on nasal discharge, headache, coughing, general health and to some extent sneezing when age, gender, BMI and reported co-morbidity levels were adjusted for.

Conclusion: A clinical implication of this is that patients with EDS may be evaluated and treated for sino-nasal disease, while medical and surgical measures to open the nose per se may not be effective therapeutic options. A scientific implication is that the relationship between SRBD and sino-nasal disease should be further investigated.

Key words: Nasal obstruction, excessive daytime sleepiness, visual analogue scale, peak nasal inspiratory flow, Epworth sleepiness scale, sleep disordered breathing.

\section{Introduction}

Excessive daytime sleepiness (EDS) is defined as inability to maintain wakefulness and alertness during the major waking episodes of the day, with sleep occurring unintentionally or at inappropriate times almost daily for at least three months ${ }^{(1)}$. The prevalence of excessive daytime sleepiness was $17.7 \%$ in the general adult Norwegian population ${ }^{(2)}$. There are several major causes of EDS. It may be due to insufficient sleep, to a variety of sleep disorders, neurological disorders, medical and genetic disorders as well as psychiatric disturbances. A number of medications may, as well, induce EDS, either therapeutically or as a side effect. The condition may have diverse and serious consequences. It is estimated that up to $52 \%$ of single vehicle crashes involving heavy trucks may be related to EDS ${ }^{(3)}$. Sleepy students have significant lower levels of academic performances and lower graduation rates than other students ${ }^{(4)}$. Daytime sleepiness has also been linked to poor health, including an association with sleep characteristics and metabolic abnormalities that are risk factors for cardiovascular diseases and lifetime depressive disorders ${ }^{(5,6)}$. Accordingly, EDS is a common problem with widespread behavioral and medical implications that is important to recognize and address.

Nasal obstruction is also a common complaint. It represents a key symptom of many upper airway disorders. It may significantly affect quality of life and facilitates oral breathing ${ }^{(7,8)}$. The nose accounts for more than $50 \%$ of the total airway resistance, and is important for humidification, heating and filtration of the inspired air, as well as for regulating of essential pulmonary 
functions ${ }^{(9)}$. Despite the fact that nasal congestion is a widespread and important clinical finding, its grading is in most instances based solely on the subjective notion of the patients or investigator. For objective quantification, acoustic rhinometry (AR), rhinomanometry and Peak Nasal Inspiratory Flow (PNIF) are valuable instruments.

The role of the nose and sino-nasal disorders in excessive daytime sleepiness is disputed. There are numerous reports about associations between nasal obstruction and sleep disorder. Epidemio $\neg$ logical studies have demonstrated a relationship between measures of nasal airflow and snoring ${ }^{(10)}$, but attempts to find a linear correlation between nasal obstruction and sleep related breathing disorders (SRBD) have been less successful (11). Results of the GA2LEN study from Sweden found that the prevalence of sleep problems and daytime symptoms was substantially higher among subjects with chronic rhinosinusitis compared with the total population ${ }^{(12)}$. A weak correlation between nasal resistance measured by posterior rhinomanometry and severity of obstructive sleep apnea syndrome (OSAS) has recently been reported ${ }^{(13)}$. Recently, it was demonstrated that patients with CRS and concomitant obstructive sleep apnea (OSA) have substantial disease-specific QOL improvements after surgical treatment of the former ${ }^{(14)}$.

However, the precise nature of this relationship remains to be clarified. As impairment of sleep leading to daytime sleepiness and nasal obstruction are both prevalent disorders, coexistence is to be expected in a number of patients. Whether this coexistence is incidental or causative remains to be an unsettled question in respiratory medicine today.

Identifying a link may be important to optimize the investigation, treatment and follow up of patients with EDS. If causality between nasal function and EDS can be proven, this can lead to new therapeutic strategies.

Epworth Sleepiness Scale (EpSS) is an instrument frequently used to assess the severity of daytime sleepiness. This study is aimed to further explore the role of nasal function in EDS by investigating the correlation between patient reported sino-nasal symptoms and nasal airflow and EpSS.

\section{Materials and methods}

\section{Material}

651 patients referred to the Dept. of Otolaryngology, Head and Neck Surgery, Sørlandet Hospital, Kristiansand Norway with EDS on suspicion of SRBD were consecutively included after informed consent. The suspicion was based on the symptoms nighttime snoring, daytime sleepiness, and nighttime episodes of sleep apneas ${ }^{(15)}$. There were 458 males and 193 females. The mean \pm SD age was $46.5 \pm 12.0$ years (range: $19-81$ years) (Figure 1). $17.8 \%$ had an apnoe-hypapnoe-index (AHI) below $5.0,82,2$ above, the latter indicating Obstructive Sleep Apnea Syndrome (OSAS). Table 1 shows self-reported co-morbidities.
Patients referred for the investigation of nasal obstruction only, were not included to the study.

\section{Methods}

Epworth sleepiness scale (EpSS)

EpSS is a simple and rapid method for measuring degree of daytime sleepiness. EpSS is a patient reported measure of sleepiness (16). It presents eight different situations about sleepiness that are commonly met in daily life. A higher total score (range 0-24) indicates increased degree of sleepiness ${ }^{(17)}$. The employed EpSS cut-off score separating those with normal versus excessive level of daytime sleepiness is $11^{\text {(2) }}$. Several studies have shown that EpSS questionnaire is a reliable method for assessing daytime sleepiness and to demonstrate the response of treatment ${ }^{(18,19)}$.

\section{Nose symptom Visual analogue scale (Nose-VAS)}

VAS is a common scoring method for patient-reported symptoms, and widely used in order to evaluate outcome in studies. VAS is a psychometric response scale to measure the intensity of various symptoms. Nose-VAS is a questionnaire developed to be used to quantify the patient reported level of nasal obstruction, as well as other sino-nasal related symptoms on a $100 \mathrm{mmm}$ linear scale ranging from no obstruction/no symptom to complete obstruction/ most intense symptom possible ${ }^{(20)}$. In the present study questions about the following 9 symptoms were included: Nasal obstruction, nasal secretion, headache, mid-facial pain, coughing, sneezing, sense of smell, complains with sinusitis as well as general health.

The patients were asked to grade their symptoms the last two weeks.

Peak nasal inspiratory flow (PNIF)

PNIF is a simple, non-invasive, fast, readily available, and easily performed method to assess nasal patency by using a Youlten Peak flow meter. PNIF is expressed in L/min and is defined as the maximal airflow achieved during forced inspiration though the nose. It consists of a face mask which the patient applies over the nose and mouth with the mouth closed and measures the peak nasal flow of air during forced inspiration.

The method was performed with the patient in orthostatic position in a room with a temperature of $20^{\circ} \mathrm{C}$ and after 10 minutes resting time. The mean of three satisfactory maximal nasal inspirations were recorded. Ottaviano et al. in 2006 reported mean PNIF value of $120-140 \mathrm{~L} / \mathrm{min}$. among healthy subjects ${ }^{(20,21)}$.

\section{Decongestion}

To assess the extent of nasal mucosal swelling and its effect on Nose-VAS and PNIF, these parameters were measured before and 15 minutes after decongestion with one spray with oxymetazoline in each nostril. 
Table 1. Reported responses to questions (yes/no) asking about present co-morbidity among the included patients.

\begin{tabular}{|lccc|}
\hline Presence of & Yes & No & $\begin{array}{c}\text { Pearson cor- } \\
\text { relation with } \\
\text { ESS }\end{array}$ \\
\hline Allergy & 191 & 419 & 0.03 \\
\hline Asthma & 59 & 547 & 0.05 \\
\hline Cardiac disease & 49 & 557 & 0.05 \\
\hline Hypertonia & 133 & 477 & $0.13^{* * *}$ \\
\hline Any medication & 22 & 583 & -0.01 \\
\hline Smoking & 224 & 393 & $-0.11^{* *}$ \\
\hline Age & Mean & SD & \\
\hline Pack-years & 46.5 & 12.0 & -0.01 \\
\hline Alcohol (1-4) & 6.2 & 11.2 & $-0.09^{*}$ \\
\hline BMl & 1.44 & 0.8 & -0.05 \\
\hline
\end{tabular}

${ }^{*}=\mathrm{P}<0.05 ;{ }^{* *}=\mathrm{P}<0.01 ;{ }^{* * *}=\mathrm{P}<0.001 ; \mathrm{ESS}=$ Epworth sleepiness scale $\mathrm{SD}=$ Standard deviation

\section{Statistics}

We used a commercially available statistical program package (IBM Corp. Released 2012. IBM SPSS Statistics for Windows, Version 22.0, Armonk, NY, USA). Figures are reported as mean \pm standard err of the mean (SEM) or mean \pm standard deviation (SD). Statistical significance was considered if $p<0.05$. All P-values reported represent two-sided tests. Cronbach alpha, Pearson correlation, Partial correlation, Factor analysis and Student t-test were calculated as indicated.

\section{Results}

\section{Patient characteristics}

The patients responded to a questionnaire about co-morbidity. Of the 651 included patients 191 stated to have allergy, 59 asthma, 133 hypertension, 49 cardiac disease and 22 kidney disease. In addition, 339 reported to be on any medication (Table 1).

\section{Epworth sleepiness scale psychometrics}

The mean \pm SD score was $10.3 \pm 5.0$ (range: 0 -24). EDS with a cut of at 11 points was present in $43 \%$ of the patients. The score distribution is shown in Figure 1. The Cronbach alpha score was 0.83. The Epworth sleepiness scale individual scores were subjected to factor analysis where one factor reached an Eigenvalue above 1.0. This factor accounted for $47 \%$ of the variance.

\section{Nose-VAS psychometrics}

Cronbach alpha including all questions was 0.72 . Table 2 shows results from a factor analysis including these questions. In Table 2 , the two most right columns show the results of the factor
Gender

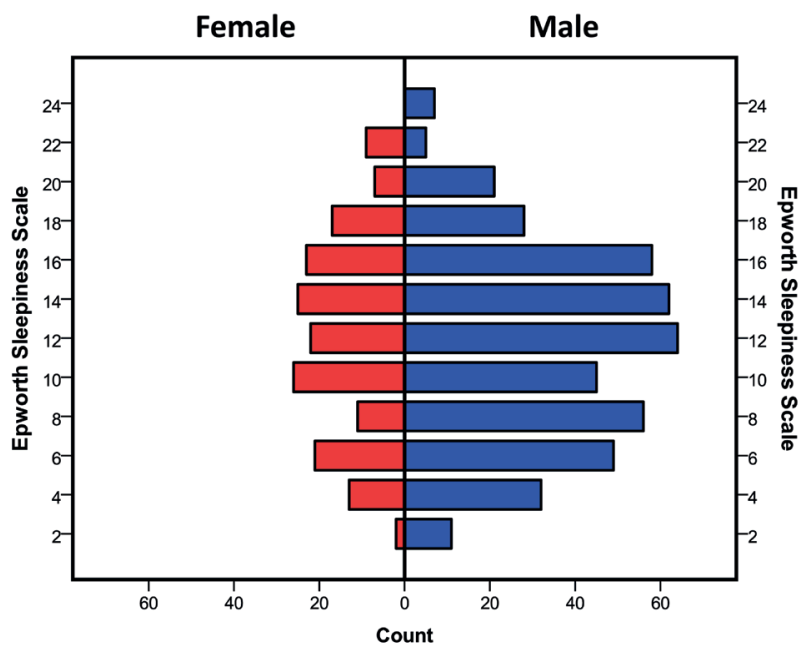

Figure 1. Number of included patients by gender and Epworth Sleepiness scale (EpSS).

analysis.

Correlation between EpSS, reported nasal congestion and PNIF scores

A Pearson correlation matrix was calculated between the Epworth sleepiness score, the included Nose-VAS questions and PNIF scores and shown in Table 3. As can be seen, significant correlations were shown between the different Nose-VAS questions. The significant correlations ranged between $0.15(p<0.001)$ and $0.44(p<0.001)$. As expected, the PNIF scores correlated inversely with the reported level of nasal congestion $(p<0.001)$. Patients reporting most nasal obstruction had, as a group, lower PNIF scores than those reporting patent noses. Measured were $84.5 \pm 1.5$ (mean \pm SEM) versus $73.8 \pm 2.3 \mathrm{~L} / \mathrm{min}(\mathrm{p}<0.001)$ at baseline, and $95.8 \pm 1.3$ versus $87.9 \pm 2.2 \mathrm{~L} / \mathrm{min}(\mathrm{p}=0.002)$ after decongestant application (Figure 2). Additionally, the PNIF scores correlated with the "general health" score $(p<0.01)$.

Regarding the EpSS score, EpSS was positively correlated to level of nasal secretion $(p<0.05)$, headache $(p<0.01)$, coughing $(p<0.05)$, sneezing $(p<0.05)$ as well as the reduced general health $(p<0.01)$.

The reported nasal obstruction both before and after de-congestion was not significantly correlated with EpSS (results not shown). Similarly, PNIF levels did not significantly correlate with EpSS scores neither before nor after de-congestion (results not shown).

Partial correlation analyses were also performed including the above mentioned significant correlations which gender, age and from Table 1 reported co-morbidities without altering determined significance levels (results not shown).

We also divided the patients into two groups based on EpSS score with 11 as cut off (Figure 3). By this approach we found 
Table 2. Mean and SD score as well as results factor analysis including NOSE-VAS questions.

\begin{tabular}{|lcccc|}
\hline Nose-VAS questions & \multicolumn{2}{c}{ Scores } & $\begin{array}{c}\text { Components from } \\
\text { factor analysis }\end{array}$ \\
& Mean & SD & I & II \\
\hline Nasal congestion & 41.3 & 26.0 & 0.635 & \\
\hline Nasal secretion & 29.5 & 26.6 & 0.600 & \\
\hline Headache & 35.5 & 29.1 & & 0.785 \\
\hline Mid-facial pain & 18.4 & 24.0 & & 0.796 \\
\hline Sinusitis & 17.8 & 23.7 & 0.305 & 0.600 \\
\hline Coughing & 32.1 & 26.0 & 0.627 & \\
\hline Sneezing & 37.5 & 25.0 & 0.663 & \\
\hline Decreased sense of smell & 33.9 & 29.8 & 0.636 & \\
\hline General condition & 31.8 & 29.3 & & 0.588 \\
\hline
\end{tabular}

a Result from principal component factor analysis (rotated Warimax solution) with minimum Eigen value $=1$. Kaiser-Meyer-Olkin measure of sampling adequacy: 0.786 . Barlett's test of Sphericity: Chi-square $=1001$ D.F.: $36, p<0.001$.

that low level of headache was associated with low EpSS scores $(p<0.05)$. The same was the case with level of nasal discharge $(p<0.01)$, level of coughing $(p<0.05)$ and reduced general condition $(p<0.001)$. The same was to some extent the case with level of sneezing $(p=0.067)$

\section{Discussion}

In this paper we investigated the associations between daytime sleepiness, and self-reported symptoms of sino-nasal dysfunction, including nasal obstruction, nasal discharge, headache, mid facial pain, rhino-sinusitis, coughing, sneezing, reduced sense of smell, and reduced general health, as well as peak nasal inspiratory flow. The aim was to further clarify the much disputed role of the nose in sleep disturbances. No correlation was found between daytime sleepiness and reported nasal obstruction or measured nasal airflow. There were associations between daytime sleepiness and nasal discharge, headache, coughing, sneezing and general health.

Firstly, the employed questionnaire measuring daytime sleepiness by EpSS showed excellent psychometric properties with a high Cronbach alpha and one component formed in the factor analysis. This shows that this questionnaire may yield valid information in the investigated group. Furthermore, the patient EpSS score distribution approached a natural distribution, indicating that the scores reflect natural variation rather than separate a diseased group from healthy controls.

Secondly we employed a Nose-VAS questionnaire with many of the same directly nose-related questions as used in the SNOT20/22 questionnaire ${ }^{(22)}$.
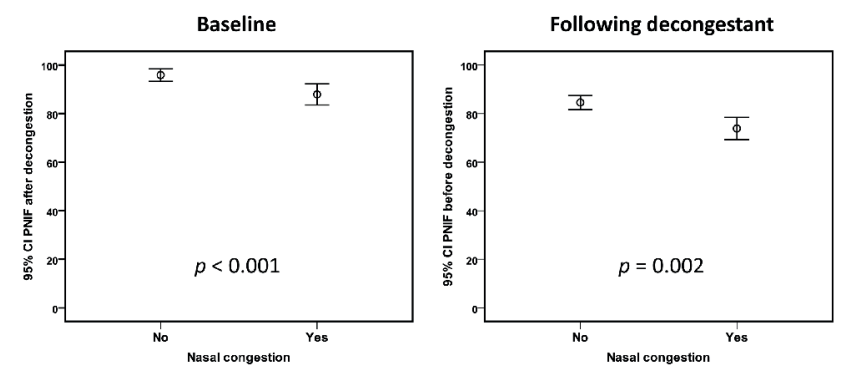

Figure 2. Peak nasal inspiratory flow (PNIF) by reported nasal congestion at baseline and following nasal de-congestion.
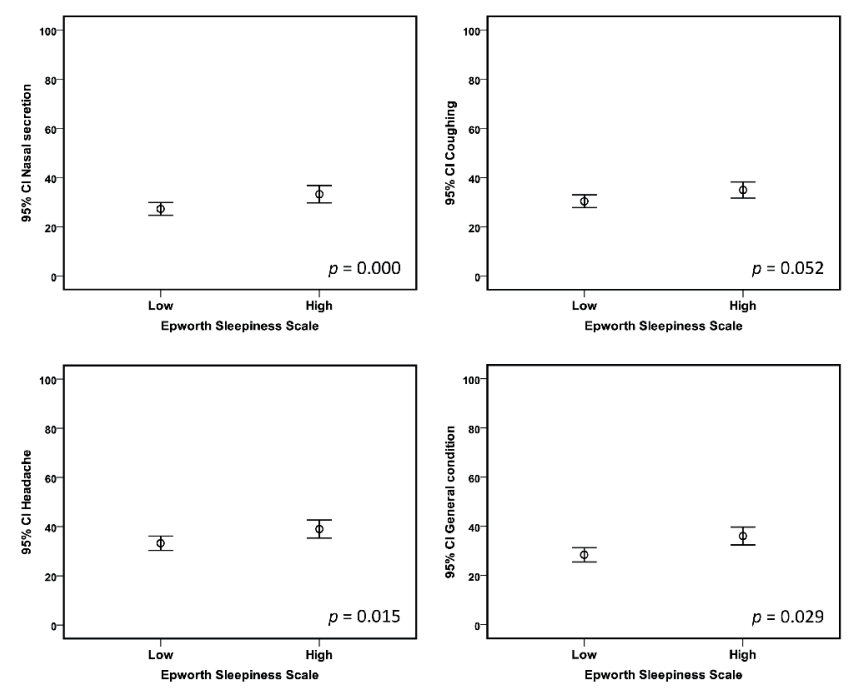

Figure 3. Reported level of indicated nasal symptoms (NOSE-VAS) by reported level from ESS (scored by a cut off of 11).

We have firmly shown that patients with excessive daytime sleepiness as measured by EpSS report more symptoms of nasal dysfunction than patients with normal daytime sleepiness.

There are particularly 3 patho-physiological mechanisms that potentially may explain a role of the nose in excessive daytime sleepiness ${ }^{(16)}$. These are the Starling resistor model and the unstable oral airway, the nasal ventilator reflex and the role of nitric oxide (NO). As to the Starling resistor model and the unstable oral airway, the upper airway is viewed as a hollow tube with an obstructive part anteriorly, the valve area, and a collapsible part posteriorly, the oropharynx. During inspiration, suction forces will be generated that gives an oropharyngeal collapse in predisposed individuals. In this perspective we would have expected to find a correlation between self-reported Nose-VAS, PNIF and EpSS, which we did not. Concerning NO, this is a factor facilitating nasal ventilation through maintaining the pharyngeal muscle tone, it stimulates spontaneous respiration, it has a role in sleep regulation, and it increases the oxygen exchange capacity ${ }^{(23,24)}$. NO is mainly produced in the nose and the sinuses and thus nasal respiration is crucial to make it available. NO is an example of a strong physiological driver towards the nose as the 
Table 3. Pearson correlation matrix between ESS (Epworth sleepiness scale), VAS-Nose and PNIF (Peak nasal inspiratory flow at baseline) scores.

\begin{tabular}{|c|c|c|c|c|c|c|c|c|c|c|}
\hline & Epworth & $\begin{array}{l}\text { Nasal } \\
\text { conges- } \\
\text { tion }\end{array}$ & $\begin{array}{l}\text { Nasal } \\
\text { secretion }\end{array}$ & Headache & $\begin{array}{l}\text { Mid-facial } \\
\text { pain }\end{array}$ & Sinusitis & Coughing & Sneezing & $\begin{array}{c}\text { Reduced } \\
\text { sense of } \\
\text { smell }\end{array}$ & $\begin{array}{l}\text { General } \\
\text { condition }\end{array}$ \\
\hline $\begin{array}{l}\text { Nasal } \\
\text { congestion }\end{array}$ & 0.03 & & & & & & & & & \\
\hline Nasal secretion & $0.10^{*}$ & $0.23^{* * *}$ & & & & & & & & \\
\hline Headache & $0.12^{* *}$ & $0.11^{* *}$ & $0.15^{* * *}$ & & & & & & & \\
\hline Mid-facial pain & 0.04 & $0.12^{* *}$ & $0.20^{* * *}$ & $0.44^{* * *}$ & & & & & & \\
\hline Sinusitis & 0.02 & $0.21^{* * *}$ & $0.25^{* * *}$ & $0.31^{* * *}$ & $0.44^{* * *}$ & & & & & \\
\hline Coughing & $0.09^{*}$ & $0.25^{* * *}$ & $0.26^{* * *}$ & $0.23^{* * *}$ & $0.23^{* * *}$ & $0.26^{* * *}$ & & & & \\
\hline Sneezing & $0.09^{*}$ & $0.19^{* * *}$ & $0.34^{* * *}$ & $0.15^{* * *}$ & $0.18^{* * *}$ & $0.27^{* * *}$ & $0.43^{* * *}$ & & & \\
\hline $\begin{array}{l}\text { Decreased } \\
\text { sense of smell }\end{array}$ & 0.07 & $0.34^{* * *}$ & $0.23^{* * *}$ & $0.16^{* * *}$ & $0.12^{* *}$ & $.24 * * * 0$ & $0.29^{* * *}$ & $0.24^{* * *}$ & & \\
\hline $\begin{array}{l}\text { General con- } \\
\text { dition }\end{array}$ & $0.15^{* * *}$ & $0.16^{* * *}$ & $0.18^{* * *}$ & $0.38^{* * *}$ & $0.31^{* * *}$ & $0.21^{* * *}$ & $0.29 * * *$ & $0.14^{* * *}$ & $0.30^{* * *}$ & \\
\hline PNIF & -0.05 & $-0.16^{* * *}$ & -0.02 & -0.05 & -0.03 & -0.05 & -0.05 & -0.01 & $-0.12^{* *}$ & -0.05 \\
\hline
\end{tabular}

${ }^{*}=\mathrm{P}<0.05 ;{ }^{* *}=\mathrm{P}<0.01 ;{ }^{* * *}=\mathrm{P}<0.001$

ventilator route of choice. One interesting hypothesis to further study is that sinus NO produced and daytime sleepiness is interwoven. Physiologically, there are strong preferences for nasal respiration, a nasal ventilator reflex. In our material there was a significant correlation between expressions of nasal dysfunction and perception of daytime sleepiness.

Excessive daytime sleepiness may be an expression of SRBD. However, several recent studies question the association between SRBD and sleepiness ${ }^{(25,26)}$. Previous studies on a potential link between SRBD and nasal function are inconclusive. Daytime nasal obstruction may represent an independent risk factor for OSAS ${ }^{(13,27)}$. However, studies have failed to demonstrate a linear correlation between the two ${ }^{(11,27-30)}$. It is still possible that nasal obstruction may be a weak risk factor for OSAS ${ }^{(27)}$. This deserves further investigation.

It has been proposed that daytime sleepiness and fatigue that are associated with allergic rhinitis, with nasal obstruction as one of the key symptoms, not only is a consequence of inflammatory mediators acting on hypothalamus, but partially may be due to impaired nasal breathing ${ }^{(10,27,31,32)}$. The present study does not support this assumption, and neither did the study from Stuck and colleagues ${ }^{(33)}$. On the other hand, high prevalence of OSAS in patients with chronic rhinosinusitis (CRS) has recently been demonstrated ${ }^{(34)}$. However, a linear correlation between severities of the diseases was not found. It has further been hypothesized that an adaptive response associated with a switch to oral breathing limits the impact of the nose in the pathogenesis of SRBD and daytime sleepiness ${ }^{(35)}$. A difference in importance between variable and fixed nasal obstruction in the pathophysiology of SRBD has also been suggested as an expla- nation for the lack of consistency in the research in this field ${ }^{(35)}$. This should be further investigated.

Medical and surgical measures to open the nose have a poor and an unpredictable effect on SRBD. This supports the lack of association between nasal characteristics patency and daytime sleepiness. As far as we are aware of, there are four double blind randomized controlled studies investigating the effect of topical nasal steroids on SRBD ${ }^{(10,32,36,37)}$.

Of these, only the study by Kiely et al. had the scientific standards necessary to bring further knowledge to the field. They did not find any improvement in snoring intensity, in sleep architecture, or in oxyhemoglobin desaturation index ${ }^{(37)}$. Furthermore, surgical correction of nasal obstruction caused by septal deviations, nasal polyps, and turbinate hypertrophy do not significantly improve polysomnographic data ${ }^{(29)}$. Koutsourelakis et al. ${ }^{(38)}$ found e.g. only a very limited success rate of nasal surgery in OSAS patients. A recent meta-analysis assessed the effects of nasal surgery on SRBD and found that nasal surgery does not improve the objective sleep indices ${ }^{(39)}$. This further supports the probable lack of the nose as a main contributing factor for SRBD.

PNIF measurements were only associated with the reported level of nasal congestion, not daytime sleepiness. It may be argued against this study that the nasal patency was evaluated with the patients in an upright and not recumbent position, as during sleep. Nasal resistance increases when moving from erect to a supine position, a phenomenon that is expected to be further amplified in patients with pre-existing nasal obstruction. It appears less likely though that this objection should have any clinical or scientific relevance. It may further be objected 
that the study did not include a doctor's characterization of the nasal cavities. It should also be mentioned that questionnaire responses from patients with chronic diseases tend to regress towards normalization over time ${ }^{(40)}$. This may very well be an important part of the explanation that numerically limited correlation has been shown between the Epworth score and the Nose-VAS scores especially because of the likely chronic nature of these symptoms. It should also be noted that the parameters "headache" and "general heath", included in Nose-VAS also may be influenced by sleep disordered themselves.

\section{Conclusion}

To conclude this study demonstrated that the level of daytime sleepiness was correlated to several nose-related symptoms, but not directly to subjective nasal obstruction or measured nasal airflow. A clinical implication of this is that patients with daytime sleepiness should be evaluated for sino -nasal diseases, while medical and surgical measures to open the nose per se may not be effective therapeutical options. A scientific implication is that the relationship between SRBD and sino-nasal disease should be further investigated.

\section{Acknowledgement}

We thank Irene Winger, Liv Henny Kyllingstad and Anne Cathrine Lønnerød for collecting the study data.

\section{Authorship contribution}

$\mathrm{KH}$ : Analyzed the data, worked with the statistics, wrote the manuscript; HKA: Supervised the statistics, supervised the manuscript; BB: Suprvised the manuscript; EHL: co-writing the manuscript; SS: Collected the data, supervised the manuscript.

\section{Conflict of interest}

The authors declare that they have no conflict of interest.

\section{References}

1. Berry RB, Budhiraja R, Gottlieb DJ, et al., Rules for scoring respiratory events in sleep: update of the 2007 AASM Manual for the Scoring of Sleep and Associated Events. Deliberations of the Sleep Apnea Definitions Task Force of the American Academy of Sleep Medicine. J Clin Sleep Med, 2012. 8(5): p. 597-619.

2. Pallesen $S$, Nordhus $\mathbf{H}$, Omvik S, Sivertsen $B$, Tell GS, Bjorvatn B. Prevalence and risk factors of subjective sleepiness in the general adult population. Sleep, 2007. 30(5): p. 619-24.

3. Pagel JF, Excessive daytime sleepiness. Am Fam Physician, 2009. 79(5): p. 391-6.

4. Pagel JF, Forister N, Kwiatkowki C. Adolescent sleep disturbance and school performance: the confounding variable of socioeconomics. J Clin Sleep Med, 2007. 3(1): p. 19-23.

5. Gangwisch JE, Rexrode K, Forman JP, Mukamal K, Malaspina D, Feskanich D. Daytime sleepiness and risk of coronary heart disease and stroke: results from the Nurses' Health Study II. Sleep Med, 2014. 15(7): p. 782-8.

6. Hayley AC, Williams LJ, Berk M, Kennedy GA, Jacka FN, Pasco JA. The relationship between excessive daytime sleepiness and depressive and anxiety disorders in women. Aust N Z J Psychiatry, 2013. 47(8): p. 772-8.

7. Corey JP, Houser SM, Ng BA. Nasal congestion: a review of its etiology, evaluation, and treatment. Ear Nose Throat J, 2000. 79(9): p. 690-3, 696, 698 passim.

8. Nathan RA. The burden of allergic rhinitis. Allergy Asthma Proc, 2007. 28(1): p. 3-9.

9. Ferris BG Jr, Mead J, Opie LH. Partitioning of Respiratory Flow Resistance in Man. J Appl Physiol, 1964. 19: p. 653-8.

10. Craig TJ, Teets S, Lehman EB, Chinchilli VM, Zwillich C. Nasal congestion second- ary to allergic rhinitis as a cause of sleep disturbance and daytime fatigue and the response to topical nasal corticosteroids. J Allergy Clin Immunol, 1998. 101(5): p. 633-7.

11. Atkins M, Taskar V, Clayton N, Stone P, Woodcock A. Nasal resistance in obstructive sleep apnea. Chest, 1994. 105(4): p. 1133-5.

12. Bengtsson C, Lindberg $E$, Jonsson $L$, et al., Chronic Rhinosinusitis Impairs Sleep Quality: Results of the GA2LEN Study. Sleep, 2017. 40(1).

13. Lofaso F, Coste A, d'Ortho MP, Nasal obstruction as a risk factor for sleep apnoea syndrome. Eur Respir J, 2000. 16(4): p. 63943.

14. Alt JA, DeConde AS, Mace JC, Steele TO, Orlandi RR, Smith TL. Quality of Life in Patients With Chronic Rhinosinusitis and Sleep Dysfunction Undergoing Endoscopic Sinus Surgery: A Pilot Investigation of Comorbid Obstructive Sleep Apnea. JAMA Otolaryngol Head Neck Surg, 2015. 141(10): p. 873-81

15. Virk JS, Kotecha B. When continuous positive airway pressure (CPAP) fails. J Thorac Dis, 2016. 8(10): p. E1112-E1121.

16. Hardinge FM, Pitson DJ, Stradling JR. Use of the Epworth Sleepiness Scale to demonstrate response to treatment with nasal continuous positive airways pressure in patients with obstructive sleep apnoea. Respir Med, 1995. 89(9): p. 617-20.

17. Johns MW. Reliability and factor analysis of the Epworth Sleepiness Scale. Sleep, 1992. 15(4): p. 376-81.

18. Johns MW. A new method for measuring daytime sleepiness: the Epworth sleepiness scale. Sleep, 1991. 14(6): p. 540-5.

19. Guimarães C, Martins MV, Vaz Rodrigues L, Teixeira F, Moutinho Dos Santos J. Epworth Sleepiness Scale in obstructive sleep apnea syndrome--an underestimated subjective scale. Rev Port Pneumol, 2012. 18(6): p. 267-
71.

20. Kjærgaard T, Cvancarova M, Steinsvåg SK. Cigarette smoking and self-assessed upper airway health. Eur Arch Otorhinolaryngol, 2011. 268(2): p. 219-26.

21. Ottaviano G, Scadding GK, lacono V, Scarpa B, Martini A, Lund VJ. Peak nasal inspiratory flow; normal range in adult population. Rhinology, 2006. 44(1): p. 32-5.

22. Piccirillo JF, Merritt MG Jr, Richards ML. Psychometric and clinimetric validity of the 20-Item Sino-Nasal Outcome Test (SNOT20). Otolaryngol Head Neck Surg, 2002. 126(1): p. 41-7.

23. Blitzer $M L$, Lee SD, Creager MA. Endothelium-derived nitric oxide mediates hypoxic vasodilation of resistance vessels in humans. Am J Physiol, 1996. 271(3 Pt 2): p. H1182-5.

24. Djupesland PG1 Chatkin JM, Qian W, Haight JS. [Nitric oxide in the nose and paranasal sinuses--respiratory tract physiology in a new perspective]. Tidsskr Nor Laegeforen, 1999. 119(27): p. 4070-2.

25. Bjorvatn B, Lehmann S, Gulati S, Aurlien H, Pallesen S, Saxvig IW. Prevalence of excessive sleepiness is higher whereas insomnia is lower with greater severity of obstructive sleep apnea. Sleep Breath, 2015. 19(4): p. 1387-93.

26. Arnardottir ES, Bjornsdottir E, Olafsdottir KA Benediktsdottir B, Gislason T. Obstructive sleep apnoea in the general population: highly prevalent but minimal symptoms. Eur Respir J, 2016. 47(1): p. 194-202.

27. Staevska MT, Mandajieva MA, Dimitrov VD. Rhinitis and sleep apnea. Curr Allergy Asthma Rep, 2004. 4(3): p. 193-9.

28. Young T, Finn L, Kim H. Nasal obstruction as a risk factor for sleep-disordered breathing. The University of Wisconsin Sleep and Respiratory Research Group. J Allergy Clin Immunol, 1997. 99(2): p. S757-62. 
29. Michels Dde S, Rodrigues Ada M, Nakanish M, Sampaio AL, Venosa AR. Nasal involvement in obstructive sleep apnea syndrome. Int J Otolaryngol, 2014. 2014: p. 717419.

30. Blakley BW, Mahowald MW. Nasal resistance and sleep apnea. Laryngoscope, 1987. 97(6): p. 752-4.

31. Lavie P, Katz N, Pillar G, Zinger Y. Elevated awaking thresholds during sleep: characteristics of chronic war-related posttraumatic stress disorder patients. Biol Psychiatry, 1998. 44(10): p. 1060-5.

32. Hughes K, Glass C, Ripchinski $M$, et al., Efficacy of the topical nasal steroid budesonide on improving sleep and daytime somnolence in patients with perennial allergic rhinitis. Allergy, 2003. 58(5): p. 380-5.

33. Stuck BA, Czajkowski J, Hagner AE, et al., Changes in daytime sleepiness, quality of life, and objective sleep patterns in seasonal allergic rhinitis: a controlled clinical trial. Allergy Clin Immunol, 2004. 113(4): p. 663-8.

34. Jiang RS, Liang $\mathrm{KL}$, Hsin $\mathrm{CH}$, Su MC. The impact of chronic rhinosinusitis on sleepdisordered breathing. Rhinology, 2016.
54(1): p. 75-9.

35. McNicholas WT. The nose and OSA: variable nasal obstruction may be more important in pathophysiology than fixed obstruction. Eur Respir J, 2008. 32(1): p. 3-8.

36. Craig TJ, Mende C, Hughes K, Kakumanu S, Lehman EB, Chinchilli V. The effect of topical nasal fluticasone on objective sleep testing and the symptoms of rhinitis, sleep, and daytime somnolence in perennial allergic rhinitis. Allergy Asthma Proc, 2003. 24(1): p. 53-8.

37. Kiely JL, Nolan P, McNicholas WT. Intranasal corticosteroid therapy for obstructive sleep apnoea in patients with co-existing rhinitis. Thorax, 2004. 59(1): p. 50-5.

38. Koutsourelakis I, Georgoulopoulos G, Perraki E, Vagiakis E, Roussos C, Zakynthinos SG. Randomised trial of nasal surgery for fixed nasal obstruction in obstructive sleep apnoea. Eur Respir J, 2008. 31(1): p. 110-7.

39. Nourizadeh NMM, Ardani AR, Rasoulian B, Rezaeitalab F, Asadpour H, Khazaeni K. The effect of nasal surgery on apnea-hypopnea index. Rev Clin Med. , 2014. 1(2): p. 75-81.
40. Aarstad HJ, Aarstad AK, Lybak S, Monge O, Haugen DF, Olofsson J. The amount of treatment versus quality of life in patients formerly treated for head and neck squamous cell carcinomas. Eur Arch Otorhinolaryngol, 2006. 263(1): p. 9-15.

Sverre K. Steinsvåg

Department of Otolaryngology

Head and Neck Surgery

Sørlandet Hospital

4604 Kristiansand

Norway

Tel: +4795880342

Fax: +4738073902

E-mail: sverre.steinsvag@sshf.no 